\title{
EMOTIONS THAT INFLUENCE PURCHASE DECISIONS AND THEIR ELECTRONIC PROCESSING
}

\author{
Domenico Consoli
}

\begin{abstract}
Recent studies have shown that most of our purchasing choices and decisions are the result of a careful analysis of the advantages and disadvantages and of affective and emotional aspects. Psychological literature recognizes that the emotional conditions are always present and influence every stage of decision-making in purchasing process. Consumers establish with company brands an overall emotional relationship and express, also with web technologies, reviews and suggestions on product/service. In our department we have developed an original algorithm of sentiment analysis to extract emotions from online customer opinions. With this algorithm we have obtained good results to polarize this opinions in order to reach strategic marketing goals.
\end{abstract}

Key words: emotions, emotional marketing, emotional brand, emotions measurement, sentiment analysis.

JEL codes: M31

\section{Introduction}

Nowadays, on customer purchasing, emotional factors are importants as classic functional aspects of product/service. Enterprises with their marketing operations try to arouse the emotions for tying the customer to brand of the company (emotional marketing). Companies adapt their business strategies to technological evolution changing. Enterprise wants to establish with the customer an emotional channel of trust and mutual collaboration. In some cases the customer works to create and design the product. With the explosion of Web 2.0, customers write their emotional opinions using several media channels (text, images, audio and video). It is interesting to analyze and process these emotions by specific software. In my department we have extract emotions from sentences included in opinions on product/service that customer express in virtual communities. We extract emotion from single word and from an entire sentence. We are also studying the emotions that can be extracted from the facial expressions.

This paper is organized as follows: in the next section is shown the literature review while in the third section we give a detailed description of the emotions and their importance in purchasing process. In the fourth section our research method for extract emotions from textual sources is discussed. The fifth and sixth sections are useful to show algorithm, experimental planning and the results. In the last section we describe scientific approach to measure facial emotions. Finally some conclusions are drawn.

\section{Literature review}

In the past, since Aristotle, many efforts have been made to emphasize the emotionalism in different fields of knowledge. For Descartes (1649), emotions were a series of automatisms and human behaviors different than cognitive processes. Descartes isn't only known for his dualism between spirit and body, between intangible mind and brain but also for the separation between reason and emotion. With the Enlightenment many philosophers considered the emotions inside the materialism of the behavior as something that places human beings close to animals. Even the

\footnotetext{
${ }^{1}$ Università Politecnica delle Marche, Dipartimento di Ingegneria Informatica, Gestionale e dell'Automazione, e-mail: consoli@diiga.univpm.it
} 
animals have emotions. After Descartes, most important studious on the emotions have been Darwin, Ekman, Damasio and Goleman.

In the 800 years, Charles Darwin (1913) was the first to provide strong basis for emotions, indicating their significance, their adaptive value, their utility and communication. Darwin believed that many of the facial expressions of emotions, have an adaptive significance (in evolutionary terms), that serve to communicate something. A person, without words, tells to others how she feels in that moment: sad, happy, scared, etc.. This has a useful meaning. For example the fear is an emotion that often indicates an hazard and it is useful to communicate to others.

The emotions are also linked to physiological aspects. Emotion is even cry, breathe more deeply, sweat, etc ....

Darwin has splitted the emotions in their basic aspects, in their expressions, their meanings, and so on. Darwin was the first author who studied emotional evolution on infants and on own children. The emotions may be more or less undifferentiated at the beginning. The infant can only feels pleasure or pain, good or bad but after, in the growth, the emotions become increasingly sophisticated and they refers to inner states of mind.

Darwin, in the book "The expression of emotions in humans and animals" says that also animals feel emotions: they have neural circuits, reactions and behaviours human similar.

Continuing the studies of Charles Darwin, the canadian psychologist Paul Ekman (2007) has confirmed that an important feature of basic emotions is that they are universally expressed, by everybody in any place, time and culture, through similar methods.

Some facial expressions and the corresponding emotions were not culturally specific but they are universal and have a biological origin.

Ekman, analyzed how facial expressions respond to each emotion involving the same type of facial muscles and regardless of latitude, culture and ethnicity. This study was supported by experiments conducted with individuals of Papua New Guinea that still live in a primitive manner.

Damasio (2001) affirms that the decisions are choices mainly emotionals. To support this assertion, Damasio shows the cases of some patients who, with neurological damage in certain brain areas, are completely unable to make a decision, despite being perfectly able to make a correct evaluation of all factors involved.

Daniel Goleman (1996) is one of the major experts in the world of emotional intelligence. Goleman, in his experiments, noted the success of people without a great cognitive intelligence of logical-mathematical type but with a strong emotional sensitivity.

\section{Emotions in the purchaising process}

In this section we describe, in detail, the emotions that customers express in the purchasing process and their measurements. In particular we consider the following sub-sections: Emotion classification (3.1), Customer emotions (3.2), Emotional intelligence (3.3), Emotional and experiential marketing (3.4), Attraction and guerrilla marketing (3.5) and Emotions measurement (3.6).

\section{Emotions Classification}

An emotion is defined as a state of psychological arousal with cognitive aspects that depend from the specific context. There are basic and complex (primary and secondary) emotions. Some authors (Ortony and Turner, 1990) consider a different number of basic emotions from two (good and bad) until about thirty. Paul Ekman, as basic emotions, consider anger, disgust, fear, joy, sadness, surprise while Zamuner (1998): joy, love, peace, compassion, anxiety, boredom, sadness, surprise, fear and anger.

The primary emotions, according to a recent definition of Robert Plutchik (1997) are eight, divided into four couples: anger and fear, sadness and joy, surprise and the waiting, disgust and acceptance. 
Bindu et al. (2007), with their model of emotions recognition from facial expressions, have classified 22 emotions: Happy, Pride, Enthusiasm, Joy, Love, Tenderness, Ecstasy, Lust, Surprise, Conformity, Boredom, Inldifferenlce, Disgust, Fear, Revenge, Rage, Sadness, Hate, Grief, Shame, Sorrow, Anger.

From the variations, shades, nuances of primary emotions it is possible arise others complex emotions: cheer, shame, anxiety, resignation, jealousy, hope, forgiveness, offense, nostalgia, remorse and disappointment.

In the natural language, there are many words of a language that contain, in their semantic representation, information about an emotional state. If we split the phrase in part of speech (names, verbs, adjectives,..), we can consider different emotional terms: names (fear, awe, gratitude, disorientation), verbs (admire, hate, get angry, rejoice), adjectives (angry, furious, sad, happy), adverbs (sadly, joyfull), interjections (ooh, perbacco).

The emotional stimuli may be an event, a scene, a face, a poster, an advertising campaign. These events, as a first reaction, put on alert the organism with somatic changes as heart rate, increase of sweat, acceleration of respiratory rhythm, rise of muscle tensions.

The emotional stimuli (Aharonson et al., 2007) are simultaneously sent from the thalamus to the associative cortex, where they are processed in a slower but more refined way. At this point, according to the assessment, a type of response, considered most appropriate to the situation, is given.

Emotions give an immediate response that often don't use cognitive processes and conscious elaboration but sometimes they have an effect on cognitive aspects as concentration ability, confusion, loss, alert, and so on. The face and the verbal language can reflect the outside deepest emotions: a trembling voice, a tone altered, a sunny smile, the face corrugated.

In a saturated market, the desires are more important than needs and thus the state of mind, the emotions, sympathies become predominants. Besides quality and price, the consumer wants trust, love, dreams (intangible factors).

\section{Customer emotions}

The emotion becomes more important with the emergence of the principle of the consumer pleasure. The emotions represent another form of language universally spoken and understood. Emotions are a distinctive element that must be added to enhance the basis supply of product/service and especially they are designed and managed with rigor and ethical spirit.

The consumer doesn't looks for a product/service that meets both the needs and rational processes, but for an object that becomes a center of symbolic meanings, psychological and cultural, a source of feelings, relationships and emotions.

The purchase decisions of customers are driven by two kinds of needs: functional needs satisfied by product functions and emotional needs associated with the psycological aspects of product ownership. The products must generate emotions but also present good functionality (traditional attributes).

Nowadays, products of different companies are equals; it is necessary to diversify them with other factors (Jordan, 2001). For example people don't consider only the product cafè, ice-cream but consider how (with music, fragrances,..) and in which context they drink a cafè or they eat an ice cream (Li and Sy, 2009).

The company will not sell a simple perfume but one component of a complex supply that consists on the experience to awaken all senses deriving from the use of that perfume.

In fact, we remember almost entirely the emotions, the smell, fragances and so on. In the advertising it is necessary to touch the intangible aspects of the product: forms and images are linked with a process of significations.

The companies, with their product and services want to create emotional link with consumers and establish a deep relationship and experience (Barnes et al., 2003). In the experience 
a fundamental role is played by environmental and social context, physical or virtual store, in which the interaction takes place.

The generation of emotions normally passes through the multisensorial involvement of the subject: music, materials, fragrances, colors, tastes, visual merchanding and symbols of various type.

\section{Emotional Intelligence}

The emotional intelligence is a form of intelligence non-rational, related to ability and to emotional feelings. Subsequently we use it in a conscious and rational way; it is a form of intelligence, non logic, but with a strong emotional charge.

The awareness of own emotions and their recognition is a key element to make a relationship based on social exchange and on ability to create empathy, biunivocal or one-to-many relationship.

The concept of emotional intelligence, described by Howard Gardner, has been recently developed by Daniel Goleman (1996) with the best seller "Emotional Intelligence: Why It Can Matter More Than IQ". Goleman says that intelligence based on pure rationality is only one aspect of more general skills that enable people to respond to various situations and to solve relative problems.

Between an object and a person an empaty relationship is etablished. The empathy is the ability to understand feelings of other person. The word derives from the greek " $\varepsilon \mu \pi \alpha \theta \varepsilon \imath \alpha "$ (empathy is a feeling "inside" a person). This term was used to indicate the emotional relationship that ties the author-singer to his audience. With adaptability and empaty a person can understand his inner experience and that of others people.

Goleman's model, as a wide array of competencies and skills, outlines four main constructs (Table no. 1):

Table no. 1

\section{Main costructs of Goleman's model}

\begin{tabular}{|l|l|}
\hline \multicolumn{1}{|c|}{ Costructs } & \multicolumn{1}{c|}{ Description } \\
\hline Self-awareness & Ability to read emotions and recognize their impact \\
\hline Self-management & Involves emotions and impulses control and adapting to changing circumstances \\
\hline Social awareness & $\begin{array}{l}\text { Ability to sense, understand, and react to others emotions while comprehending } \\
\text { social networks }\end{array}$ \\
\hline Relationship management & Ability to inspire, influence, and develop others in the conflict management \\
\cline { 2 - 2 } & \multicolumn{1}{|c|}{ Source: Goleman model, 1996 (adapted by author) }
\end{tabular}

Mayer et al. (2008) give the following definition of EI: "The ability to perceive emotion, integrate emotion to facilitate thought, understand emotions and to regulate emotions to promote personal growth". The ability-based model considers emotions as useful sources of information that help one to make sense of the social environment.

The model proposed from authors includes 4 types of abilities (Table no. 2):

Table no. 2

\section{Main abilities of Mayer et al. model}

\begin{tabular}{|l|l|}
\hline \multicolumn{1}{|c|}{ Abilities } & \multicolumn{1}{c|}{ Description } \\
\hline Perceiving emotions & $\begin{array}{l}\text { ability to detect and decipher emotions in faces, pictures, voices, and cultural } \\
\text { artifacts. }\end{array}$ \\
\hline Using emotions & $\begin{array}{l}\text { ability to harness emotions to facilitate various cognitive activities, such as } \\
\text { thinking and problem solving }\end{array}$ \\
\hline Understanding emotions & $\begin{array}{l}\text { ability to comprehend emotion language and to appreciate complicated } \\
\text { relationships among emotions. }\end{array}$ \\
\hline Managing emotions & ability to regulate emotions in both ourselves and in others \\
\hline
\end{tabular}

Source: Mayer model, 2008 (adapted by author) 
Therefore, a person with emotional intelligent can harness emotions, also negative and manage them to achieve specific goals.

\section{Emotional and Experiential Marketing}

The use of Emotional Marketing as a strategy of Relational Marketing ensures, both a deep and personal relationship with the customers acquired on emotional aspect and the retention of a competitive position on the market.

Nowadays itsn't the product to be sold, since for each category there is a wide choice, but the focus is the relationship that the consumer establishes with the brand and with the emotions which the product communicates. In this regard Fabris sustains that "the consumer has changed skin or skin is changing, looking experiences rather than products or sensations and emotions rather than use values" (Fabris, 2009).

Brands become supplying centers of emotional energy, which create better relationships with potential consumers with the ability that they have to tell stories that excite (emotional brands) and integrate communication, quality, tradition, identity (brand sensivity).

Emotional marketing answers questions like "What are the attitudes, behaviors, preferences and emotions of those who make purchases? ", "Can we measure their emotions before during and after the purchase? ", "How does the mind of consumers reacts when it is stimulated by advertising, promotion, while they are in a supermarket or navigate in an e-commerce site?".

Enterprises, to stimulate emotions in customer, use multimedia channels. A person can be receptive to graphs another to auditory or video stimuli.

Recently, marketing studious have noted that the olfaction is very important in purchasing decisions. In many cases it is important to put inside the stores certain odors or musics.

Smells are a powerful media for their ability to imprint a long time in memory. For real estate agents, to show and sell apartments, are important the aromas of coffee or cake in the oven; these smells activate positive emotions related to concepts such as "childhood", "mother" and so on. The department stores spray perfumes of field to slow down the purchases of the customers. Even the music is strongly interrelated with the emotions and its usefulness for commercial purposes is well known.

Summer is for definition a period of more dense emotions: sun, sea, beautiful scenery, fun, new friendships, new loves. The advertising arouse sensations on products such as slimming creams, suntan lotion, toning, smoothing and also with a new ice cream, tasty and coloured or on the new ice tea with exotic fruits.

In the emotional marketing one of the first targets is to identify the type of experience (Mailund and Halskov, 2008) that emphasize the best product and the creation of the empathy between company and customer, such as to increase both the involvement of the consumer and the perceived differentiation.

Schmitt (2003) identifies 5 different types of experience (Table no. 3):

Table no. 3

Main experiences of Mayer et al. model

\begin{tabular}{|c|l|}
\hline $\begin{array}{c}\text { Type of } \\
\text { experiences }\end{array}$ & Description \\
\hline Sense & experiences that involve sensory perception \\
\hline Feel & experiences that involve the feelings and emotions \\
\hline Think & cognitive and creative experiences \\
\hline Act & experiences that involve physicality \\
\hline Relate & experiences resulting from the relationship with a group \\
\hline
\end{tabular}

Source: Schmitt model, 2003 (adapted by author)

The types of experience listed above can be combined together creating hybrid or holistic experience. 
Experiential Marketing is a useful tool in many situations including, for example, the revitalization of a brand in decline or the creation ex-novo of the image and identity of a company. Experiential marketing represents a new source of competitive advantage, based both on emotional involvement and on creation of experiences. This strategy focuses on the marketing function of the consumer.

To improve relationship it is essential that companies clearly define their target and acquire skills relevant to other disciplines not purely economic such as psychology and sociology. It is need a close interaction with the consumer, knowing the particular experiences that people would like live.

\section{Attraction and Guerrilla Marketing.}

The Attraction Marketing (AM) (Lam et al., 2001) bases on the concept that the relationship between brand and consumer is the same between people. For example many people affirm that Fiat 500 is very interesting. They love it; it's fantastic. The brands must be able to talk directly to heart of the people. In this way, also products very cheap could compete with products more preciouses and very expensives.

People choose brands, not for their functions, but for their significance, the role that play in their lifes. For the prosperity of the brand it is necessary a creation of a long-term and a deep emotional relationship between enterprise and consumers thus creating an affective dependence.

The brand must create empathy and passion in order to generate in the customers a true emotional loyalty. If the brand will hear the consumers with more attention to feedback, one day the brand will be created by the consumer himself.

Enterprises want also to provide a social product for helping the local community against any type of environmental pollution.

Guerilla Marketing (GM) is a definition coined by Jay Conrad Levinson (2008) to indicate a form of advertising unconventional and with low-budget, achieved through the creative use of resources and tools aggressives that influence the psicology of the consumers.

The methodology used focuses on the psychology of individuals rather than on their experience and their ability to express an opinion. Guerrilla use tactics, such as surprise and persuasion, to create strong messages that can capture the attention and interest of the users. GM reaches the consumer in times and places where their defenses against advertisements are lowered. The impact of the message must be absolutely unconventional and direct. The final goal is to create viruses capable of replication and to contaminate, as much as possible, the community of customers in a word of mouth and a viral marketing.

6. Emotions measurement

The emotional reactions of our brain are measured through a series of techniques, biometric stimuli, that in combination with interpretations of psycholinguistics and cognitive psychology, explain the unconscious reactions of the consumer towards the brand.

The techniques of emotions measurement (Boehner et al., 2007) depend on application field. Many kinds of physiological characteristics are used to extract emotions, such as voice, facial expressions, textual expression, hand gestures, body movements, heartbeat and blood pressure.

In this paper we have mainly measured the emotions that come from textual sources; we are going to study also facial emotions.

The text is an important modality for detecting emotional aspects because, today, many user interfaces are textually based.

Textual information is a communication medium, rich in emotion, that can be retrieved from many sources, such as books, newspapers, web pages, e-mail messages, etc... Nowadays textual channels are used in intensive manner in the virtual communities (drivers of social emotions).

For example, many customers express their opinions on product/service by web 2.0 tools (forum, chat, blog). The customer when writing his reviews transmits emotions in the message that he/she feels before and after the product purchasing.

So from an enterprise point of view it is important to understand which emotional coefficients drive the customer to choose a particular product/service. 
To extract emotions from textual opinions, useful for business strategic planning, we can use different software that implement algorithms for mining opinion or sentiment analysis.

Each word of text expresses sentiments and emotions, in an direct or indirect manner, and from singular word after we can extract a polarity (positive or negative) of phrase and of the whole post.

\section{Research metodology}

In our department we have developed an original algorithm of sentiment analysis to extract emotions from textual customer opinion expressed in virtual communities. Our algorithm mainly focuses on six Ekman emotional indexes (Consoli et al., 2008):

happiness, surprise, fear, sadness, anger, disgust.

Ekman, use these indexes for the study of facial expressions subsequently a certain emotional state. He noticed that all human beings respond with the same facial movements to the same emotional states that derive, from the main six emotions.

In our opinion, these indexes, allows to better capture the emotional state of customers about purchase.

For example, in luxury goods, the emotional aspects as brand, uniqueness and prestige for purchasing decisions, are more important than rational aspects such as technical, functional or price. In this case customer is happy to buy also with high prices. Customer don't buy products disgusting. The disgust is a repugnance toward any object, action or person.

Our algorithm can be split in two stages: pre-processing and opinion polarity. Since opinions are written in Natural Language, to process them, we need specific pre-processing techniques. The goal of this phase is to obtain for each opinion significant words. The preprocessing consists of the following steps: elimination of stop words, sentence extraction, statement extraction, tokenization, stemming, lemmatization, part of speech (Berry and Castellanos, 2007). From every web post, eliminating all interrogative clauses, we extract minimum statements (phrase with an unique positive or negative opinion). For example the sentence "The restaurant is beautiful but the waiters are ungracious" may be splits into 2 statements with different polarity: "The restaurant is beautiful" (positive polarity), "but the waiters are ungracious "(negative polarity).

After we divide statements in single tokens or words. With stemming and lemmatization we derive the root of words, removing affixes and endings. In the Part of Speech phase, every word of a statement is labeled by a tag with the correct part of speech: noun, verb, adjective, adverb, etc...

In our algorithm we classify words of statements in: Direct Affective Word (DAW) and Indirect Affective Word (IAW) (Consoli et al., 2009). For example, the word happiness and cheerful carry a positive emotional state; the word ice by itself doesn't convey any emotional state. If we insert in the phrase "I like ice" the word acquires a positive emotional state clearly different from "I hate the ice". The DAW group is formed by words expressing a direct emotional state in the specific domain. Other words belong to IAW group. Respect to statements we can make the same distinction: Direct Affective Statement (DAS) and Indirect Affective Statement (IAS).

In order to test the validity of our methodology we have gathered 800 posts from web forums on customer opinions about a resort in Sharm el-Sheikh and in particular we selected opinions about services: Kitchen, Restaurant, Room Service, and Administration.

After the pre-processing phase, the software saved into database 1303 statements and 2300 words. We labeled manually 900 DAS and 374 DAW. The value of affective index for each DAW or DAS varies between 0 and 10 (values controlled by the software). Zero means no affectivity while the value 10 express an highest amplitude of affectivity. For example, if we associate to the word "stench" the affective vector $(0,0,0,2,2,6)$, it means that in the definition of the affective meaning of the word stench, the elements sad and angry contribute with a small value, the element disgust with a high value and other elements don't produce any contribution.

For DAS we manually assign also a polarity value $\mathrm{p}$ between -10 and 10 . 
The polarity $(\mathrm{p})$ depend from affectivity (a) of words: $p=f(a)$. For the polarity we take in consideration amplitude and also the sign. With sign we observe if the customer is satisfied $(+)$ or unsatisfied (-). If the customer is very dissatisfied (high negative amplitude) the enterprise must intervene with urgency and priority. It is interesting for enterprise to know also the statement affectivity for following strategic moves: Fear (special promotional campaigns for closing the customer), Anger (reassure and accompany customer in post-sale paths), Sadness (gladden customer with unique gadgets), Disgust (improve immediately the product design).

\section{Algorithm and experimental planning}

In our experimental planning, we consider as training set the $50 \%$ of DAW and DAS manually assigned. Remaining $50 \%$ forms the test set. In this way we can compare manual assigned values with values calculated by software.

Other parameters that we take in considerazion are: $\mathrm{s}$ and $\alpha$ where:

-s represent a threshold of similarity. For low values, in the calculation of affectivity, we take in consideration many words respect high values of $s$

$-\alpha$ is the weight of DAW on estimation of statement affectivity

For our estimations we use the following algorithm (Table no. 4):

Table no. 4

\begin{tabular}{|c|c|}
\multicolumn{2}{|c|}{ Algorithm for affectivity and polarity estimations } \\
\hline $\begin{array}{c}\text { Goals } \\
\text { Words } \\
\text { affectivity }\end{array}$ & $\begin{array}{c}\text { For each word of test set, we search, in the vector } \\
\text { space of training set, the closest word to direct affective term } \\
\text { by a coefficient of similarity }\end{array}$ \\
\hline $\begin{array}{c}\text { Statement } \\
\text { affectivity }\end{array}$ & \multicolumn{1}{c|}{ We consider the average weight of words direct } \\
(DAW) and indirect affective (IAW) \\
polarity
\end{tabular}

Source: Consoli et al. 2009

As error in the affectivity estimation we consider the mean squared error (MSE) or Euclidean distance:

$$
\mathrm{e}=\operatorname{MSE}(\mathrm{x})=\mathrm{E}\left(\left(\mathrm{x}-\mathrm{x}_{\mathrm{s}}\right)^{2}\right.
$$

where $\mathrm{x}$ is the estimator and $\mathrm{x}_{\mathrm{S}}$ the estimated value.

For polarity estimation we consider the amplitude and the sign. The amplitude error is given from the normalized difference between assigned and estimation polarity:

$$
\mathrm{e}=\left|\mathrm{p}_{\mathrm{a}}-\mathrm{p}_{\mathrm{e}}\right|
$$

where $p_{a}$ is the assigned polarity and $p_{e}$ is the estimated polarity.

\section{Results}

In this section we show the results of our algorithm in term of estimation error for word affectivity (Fig.1), statement affectivity (Fig.2) and statement polarity (Fig.3)

In the Figure no.1 we can see as the error of word affectivity decreases with the increase of training set. The error increases with the decrease of threshold s because in the comparison there are many words, less similar, that cause errors. 


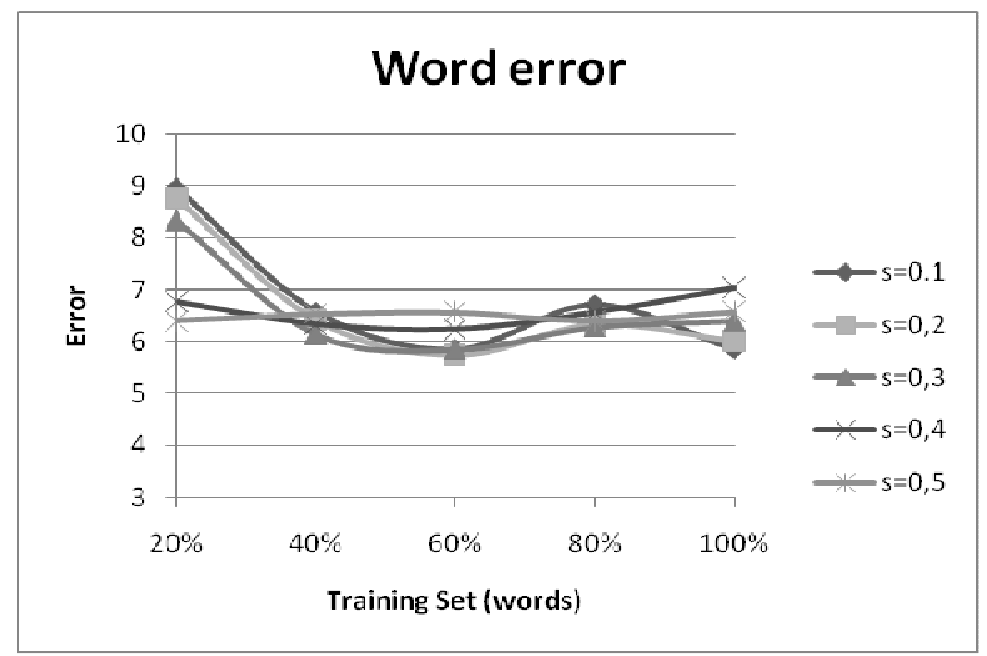

Fig. no. 1 - Word affectvity error

In the Figure no. 2 we can see as the error of statement affectivity decreases with the increase of the parameter $\alpha$ (weight of DAW). An high value of word affectivity increases the emotional component in the statement.

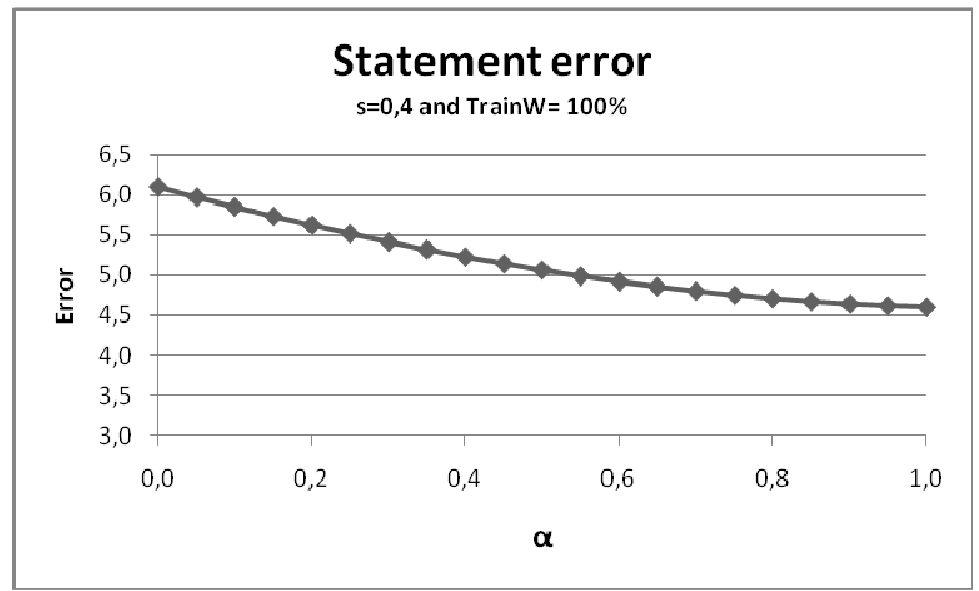

Fig. no. 2 - Statement affectivity error

The polarity error on statements, that we have calculated in our experiments, to vary of training set of statements (TrainS), is shown in Figure no.3. The figure shows that the error polarity decreases to increase of Trains. 


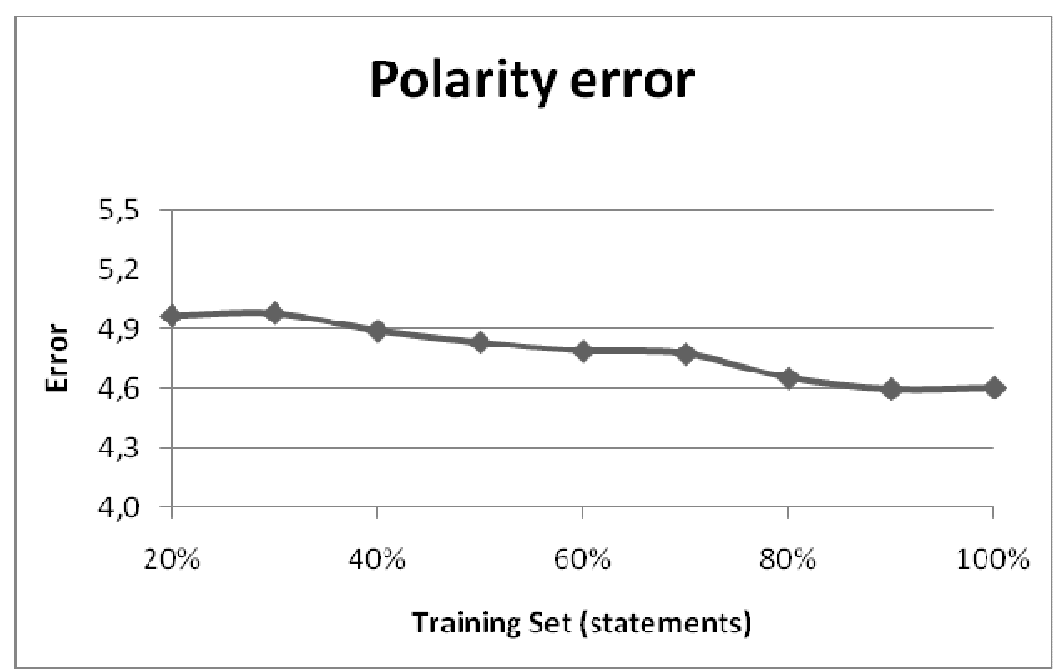

Fig. no. 3 - Statement polarity error

For best configuration of parameters (incidence of directly affective word, training set), we obtained the following errors: word error $(21 \%)$, statement error $(14 \%)$, polarity error $(22 \%)$.

These results are encouraging considering that we have used for our experiments a small training set size. The results can improve with a bigger training set, a manual labeling more rigid and with the use of polynomial regression or neural networks in the polarity estimation.

In the future, as further step to enrich our work, we are going to study an algorithm to measure also facial emotions.

\section{Facial emotions measurement}

Non-textual emotions could be measured with facial expressions, blood pressure, pupillary dilation, bio-feedback, eye-tracking and other quantifiable methods (Picard et al. 2003). To measure emotions on computers, a mathematical model is required. In the model it is necessary consider several factors concerning personality, age, experience of the people.

Facial expression recognition, coupled with human psychology and neuroscience, is an area which can connect psychology and computations.

There are two types of facial expression features (Figure no. 2), transient (wrinkles and bulges) and intransient (mouth, eyes and eyebrows).

The feature points of a face, for recognizing facial expression, are located at eyebrows, eyelids, cheeks, lips, chin and forehead.

The first and the most important step in feature detection is to track the position of the eyes. Thereafter, the symmetry property of the face with respect to the eyes is used for tracking the rest of the features like eyebrows, lips, chin, cheeks and forehead.
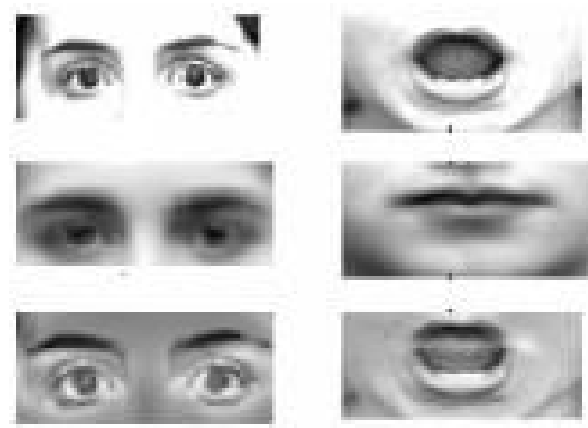

Fig. no. 2 - Facial expressions (source: Bindu et al., 2007- adapted by author) 
The face expressions, change continually; they are non-rigid and have a high degree of variability in size, shape, color and texture. Many researchs focuse on the recognition of basic emotion states of Ekman: normal, surprise, anger, happiness, sadness, (Figure 3).

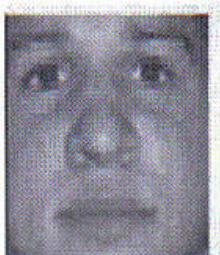

Normal

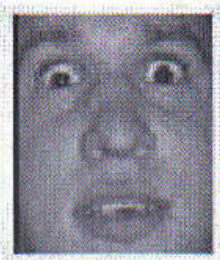

Surprise

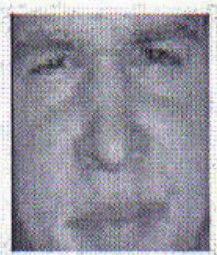

Angry

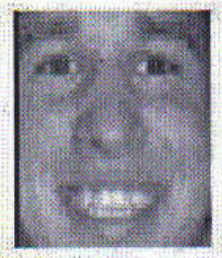

Happy

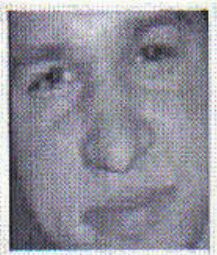

Sad

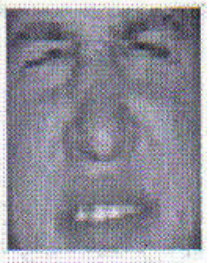

Disgusted

Fig. no. 3 - Emotional expressions (source:Tsihrintzis et al., 2008 - adapted by author)

We can identified all differences and deformations from the "neutral" expression. We can quantify these differences into measurements of the face (such as size ratio, distance ratio, orientation or texture). Specifically, we locate and extract the corner points of specific regions of the face, such as the eyes, the mouth and the brows, and compute their variations in size from neutral expression. This information can be converted in data-pixel of a higher-level representation of shape, motion, color, texture and spatial configuration and therefore saved in an appropriate database.

In a human-computer interaction context, from facial expression and therefore from information extracted from images of a person, the computer can react accordingly. The weakness of this method can be the pretence, i.e. the case of someone's facial expression not corresponding to his/her true psychological state.

Bindu et al. (2007) have created a 3-dimensional reinforcement-based model, represented with a $3 \mathrm{D}$ vector $\mathrm{V}(\mathrm{R}, \mathrm{P}, \mathrm{E})$ where $\mathrm{R}=$ Reward, $\mathrm{P}=$ Punishment and $\mathrm{E}=$ emotion. On the basis of the reinforcement, emotions are classified into two categories. The emotions produced after achieving a reward or the omission of punishment are named as positive emotions and the emotions produced after getting a punishment or the omission of a reward are named as the negative emotions. For example, happy, pride, enthusiasm etc belong to first category of emotions (positive) and sad, anger, shame etc belong to second category emotions (negative).

An other method of emotions recognition (Mauri and Lorenzon, 2008) uses 3 stages: biofeedback, eye-tracking and Cultural and Cognitive Styles (CCS).

Through bio-feedback we can monitor in real time the neuro-physiological states of subjects to the stimuli and then, with the eye-tracking, identifies, precisely, what the individual was looking at the state of activation.

The bio-feedback is a tool able of recording the state of activation of subjects submitted to a given visual stimulus and we can discriminate whether these activations are related to a situation of involvement or discomfort. Bio-feedback, that use neuroimaging techniques, is the technology by which it is possible to analyze the electrical activity that occurs in the human brain. The neuroimaging can detect, via magnetic resonance, responses of mind and the exposure to a certain product while recording the reactions of our subconscious and our cerebral activity.

The eye-tracking is a monitor, with integrated infrared cameras (not visible in any way from the outside), that tracks precisely the movements of the eyes of the person sitting in front of the monitor. Therefore eye-tracking performs a careful analysis of eye movements.

For the calibration of instruments, it is interesting to know the CCS, cognitive and cultural characteristics of a person used for testing: a very impulsive person has a propensity to stress or relax more different of a reflective person. 
To improving the accuracy on emotion recognition it is necessary a multimodal methodology (De Silva et al., 1997) text, language, audio, video and visual-facial expression. When, for example, we articulate speech we usually move the head and exhibit various facial emotions. Also the pitch and volume of voice conveys emotional information

\section{Conclusions}

In this paper we examined how emotions affect customer purchases. In recent years, many authors have intensified their studies on emotional intelligence and emotional marketing. The emotions, like the functionality of the product/service, influence the decision-making processes of customer purchasing. Nowadays the customer is very fond of the company brand with wich he/she lives unique emotional experiences. The technology, mainly web 2.0 tools, offers to customer the possibility to express their opinions and at the same time the use of a specific software can read, analyze and interpret the emotions in visual and textual manner. In the paper, we have described an algorithm, that we have developed in our department to analyze and polarize, positive or negative, textual opinions basing on emotional lexicon used in the review. As further step, we are going to measure also facial emotions.

\section{References}

1. Aharonson, V., Nehmadi, N., and Messer, H., 2007. Automatic emotional stimulus identification from facial expressions. In Proceedings of the Fourth Conference on IASTED international Conference: Signal Processing, Pattern Recognition, and Applications (Innsbruck, Austria, February). R. Sablatnig and O. Scherzer, Eds. ACTA Press, Anaheim, CA, pp. 333--337.

2. Barnes, C., Southee, C., and Henson, B., 2003. The impact of affective design of product packaging upon consumer purchase decisions. In Proceedings of the 2003 international Conference on Designing Pleasurable Products and interfaces (Pittsburgh, PA, USA, June). DPPI '03. ACM, New York, NY, pp. 134-135.

3. Berry, M. W. and Castellanos, M.. editors, 2007. Survey of Text Mining II: Clustering, Classification, and Retrieval, Springer.

4. Bindu, M.H. Gupta, P. Tiwary, U.S., 2007. "Cognitive Model - Based Emotion Recognition From Facial Expressions For Live Human Computer Interaction”, IEEE Symposium on Computational Intelligence in Image and Signal Processing, CIISP, pp. 351-356.

5. Boehner, K., DePaula, R., Dourish, P., and Sengers, P., 2007. How emotion is made and measured. Int. J. Hum.-Comput. Stud. 65, (4), pp. 275--291.

6. Consoli D., Diamantini C. and Potena Domenico, 2009. "Affective algorithm to polarize customer opinions". Paper presented at 11th International Conference on Enterprise Information Systems, Human-Computer Interaction (HCI), Milan, Italy, pp. 157--160.

7. Consoli D., Diamantini C., and Potena D., 2008. "A conceptual framework for web opinion mining". Paper presented at 5th Conference of the Italian Chapter of AIS, Paris, France.

8. Damasio A., 2001. The Feeling of What Happens: Body and Emotion in the Making of Consciousness, was named as one of the ten best books of 2001 by New York Times Book Review.

9. Darwin C., 1913. "The expression of the emotions in man and animals", D. Appleton and Company, London.

10. De Silva L., Miyasato T. and Nakatsu R., 1997. Facial emotion recognition using multimodal information, in Proc. IEEE Int. Conf. on Information, Communications and Signal Processing (ICICS), pp. 397-401.

11. Descartes, 1649. "Passions of the Soul", Hackett English edition, trans. Stephen H. Voss, 1989, pp. 24--34.

12. Ekman P., 2007. "Emotions Revealed: Recognizing Faces and Feelings to Improve Communication and Emotional Life". OWL Books, NY.

13. Fabris G., 2009. "Il nuovo consumatore: verso il postmoderno", Franco Angeli editor. 
14. Goleman D., 1996. "Emotional Intelligence: Why It Can Matter More Than IQ", Bantam Books.

15. Jordan P. W., 2001. Pleasure with products: the new human factors. In User interface Design For Electronic Appliances, K. Baumann and B. Thomas, Eds. Taylor \& Francis, Bristol, PA, pp. 303-328.

16. Lam, S. Y., Vandenbosch, M., Hulland, J., and Pearce, M., 2001 "Evaluating Promotions in Shopping Environments: Decomposing Sales Response into Attraction, Conversion, and Spending Effects". Marketing Science 20(2), pp.194--215.

17. Levinson J.C., Meyerson M., 2008."Guerrilla Marketing on the Front Lines“, Morgan James Publishing.

18. Lii, Y. and Sy, E., 2009. Internet differential pricing: Effects on consumer price perception, emotions, and behavioral responses. Comput. Hum. Behav.

19. Mailund, L. and Halskov, K., 2008. "Designing marketing experiences". In Proceedings of the 7th ACM Conference on Designing interactive Systems (Cape Town, South Africa, February). DIS. ACM, New York, NY, pp. 222--229.

20. Mauri M. and Lorenzon A., 2008. La tecnologia al servizio delle emozioni. http://www.4marketing.biz/it/2008/12/01/la-tecnologia-al-servizio-delle-emozioni/\#more-648.

21. Mayer, J.D., Salovey, P. \& Caruso, D.R., 2008. Emotional Intelligence: New ability or eclectic traits, American Psychologist, 63 (6), pp. 503--517.

22. Ortony, A., \& Turner, T. J. (1990). What's basic about basic emotions? Psychological Review, 97, pp. 315-331.

23. Picard B. R. W., Vyzas E. and Healey J, 2003. Toward," Machine Emotional Intelligence: Analysis of Affective Physiological State", IEEE Transactions on pattern analysis and machine intelligence, volume 23, number 10.

24. Plutchik, R., 1997. The circumplex as a general model of the structure of emotions and personality. In R. Plutchik and H. R. Conte (Eds.), Circumplex models of personality and emotions. Washington, DC: American Psychological Association, pp. 17-45.

25. Schmitt B., 2003. Customer Experience Management: A revolutionary approach to Connecting with Your Customers. John Willey and Sons, New York.

26. Tsihrintzis, G. A., Virvou, M., Stathopoulou, I. and Alepis, E., 2008. On Improving Visual-Facial Emotion Recognition with Audio-lingual and Keyboard Stroke Pattern Information. In Proceedings of the 2008 IEEE/WIC/ACM international Conference on Web intelligence and intelligent Agent Technology - Volume 01. Web Intelligence \& Intelligent Agent. IEEE Computer Society, Washington, DC, pp. 810-816.

27. Zammuner, V.L., 1998. Concepts of emotion: 'Emotionness', and dimensional ratings of Italian emotion words. Cognition and Emotion, 12, pp. 243--272. 